\title{
Instructional Educational Technology Improve Teaching and Learning Effective_-Building Chinese Wisdom Curriculum of Lower Grade in Primary School
}

\author{
Wang Xin \\ Education Graduate School of Education Student, National Chengchi University, Beijing, China
}

\section{Email address:}

wangxinnccu@gmail.com

\section{To cite this article:}

Wang Xin. Instructional Educational Technology Improve Teaching and Learning Effective_— Building Chinese Wisdom Curriculum of Lower Grade in Primary School. Science Innovation. Vol. 7, No. 2, 2019, pp. 64-69. doi: 10.11648/j.si.20190702.13

Received: April 20, 2019; Accepted: June 9, 2019; Published: June 15, 2019

\begin{abstract}
With the rapid development of the times and science and technology, the quality-oriented education changes emerge as the times require. Whether teaching content or teaching form and teaching means are constantly changing, the purpose is to achieve effective teaching within a limited time, to provide targeted teaching for each student to promote student development, at the same time, let students learn how to learn on the basis of learning knowledge, learn to gain. Based on the teaching practice in the classroom, this paper attempts to explore the construction of the primary school language wisdom classroom from the scientific and technological means and methods used in the teaching and learning process, so as to help teachers and students carry out effective teaching and learning in the limited curriculum, develop together and achieve win-win situation.
\end{abstract}

Keywords: Key Competences, Technology, Wisdom Curriculum, Teaching and Learning Effective

\section{以科技教学，促有效教学——浅析小学低年级语文“智慧”课堂的 建构}

\section{王釒}

台湾政治大学教育学院, 北京, 中国

\section{邮箱}

wangxinnccu@gmail.com

摘要：随着时代和科技的迅猛发展, 素养导向下的教育改变应运而生。无论是教学内容还是教学形式和教学手段都在 进行着不断地更迭, 其目的均为实现有限时间内的有效教学, 提供每个学生有针对性的教学促进学生发展, 同时, 让 学生在学会知识的基础上学会如何学习, 学有所得。本文基于课堂内的教学实践, 从教学和学习过程中使用的科技手 段、方法等进行切入, 试图探讨小学语文智慧课堂的建构, 帮助教师和学生有限的课程内进行有效的教学和学习, 共同 发展, 实现共赢。

关键词: 素养, 科技, 智慧课堂, 有效教学和学习 


\section{1. 引言}

教育部在《关于全面深化课程改革落实立德树人根本 任务的意见》中, 明确指出应使学生具备能够适应终身发 展和社会发展需要的必备品格和关键能力这一“核心素养” 导向目标。结合国情和社会需要, 在中国, 学生发展核心 素养，以“全面发展的人”为核心，分为文化基础、自主 发展、社会参与三个方面, 综合表现为人文底蕴、科学精 神、学会学习、健康生活、责任担当、实践创新六大素养。 [1] 以此落实立德树人的根本任务, 培养全面发展的人, 提 升21世纪国家人才竞争力。

早在1997年, 经济合作与发展组织(Organization for Economic Cooperation and Development, 简称 OECD)便提 出了“核心素养”这一概念, 并启动了Definition and Selection of Competencies: Theoretical and Conceptual Foundations（即“素养的界定与遴选：理论和概念基础”， 简称 DeSeCo计划)。以此为概念框架, 各国针对国情和需 要制定了本国的“素养”指标。美国的企业界联合教育界共 同提议建构“21世纪型能力” ( 21 st Century Skills) 的概念, 在学科内容的基础上, 强调“信息、媒体、技术的能力”,“生 活与生存的能力”。[2]日本的核心素养研究体现在不同阶 段的教育改革中。进入 21 世纪, 日本的教育课程改革在培 养“生存能力”的基础上, 提出了培养学生发现课程的能力, 自主学习、自主思考的能力, 解决问题的能力的重要性, 并要求适应学生的兴趣、学习的程度、发展倾向等进行个 别化指导, 推进发展个性教育。日本特色鲜明的核心素养 理论狂降就此产生 [3]

本文旨在 21 世纪的“素养教育”环境下，在技术飞速发 展的社会背景下, 探讨如何在教育实践中结合科技手段, 创新教学过程, 构建有效的小学语文课堂。

\section{2. 研究背景及目的}

\section{1. 研究背景}

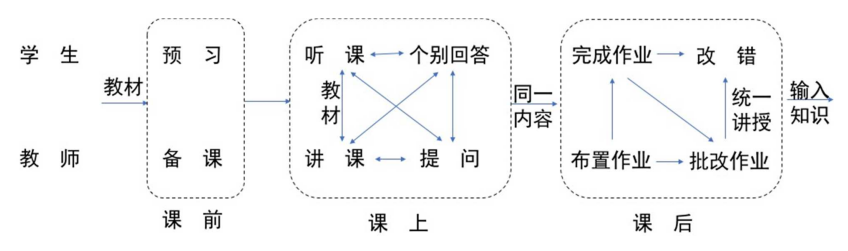

图1 传统教学模式。

传统的教学模式 (如图1) 将课堂划分成了课前、课 中、课后三个部分。以小学语文课堂为例, 在课前, 教师 会以教材中的内容或课后问题为准, 结合单元目标和课程 标准, 设计教学目标和任务进行备课, 并要求学生进行预 习。在课中, 师生间的互动仅限为提问和回答, 教师在个 别学生的答案中评断学生们的掌握情况进行引导, 以此达 到预设的教学效果。课后, 进行全班统一的作业布置和批 改讲授, 学生修改作业错误。至此, 完成一篇课文的讲授。

可见, 进行传统教学的课堂是以教师为本, 以教材为 本目的较为单一的教学活动, 通过一部分学生的参与推测 全部学生的学习效果。学生参与学习过程的范围较小, 且
过于被动, 在老师的“安排”下进行, 评量方式固化仅为统 一性的作业, 没有针对性, 无法让每名学生“一课有一得”, 在自身的基础上得到相应的提高。整体来说, 传统课堂教 学模式缺乏师生互动, 无法提供学生差异化、个性化的教 学指导, 学生学习的自主性的难以发挥, 创新性难以体现。 [4]

随着对学习过程的深入探索, 建构主义学习理论开始 在西方盛行。许多研究者和教师逐渐发现传统教学模式针 对班级内参差的学生仅仅“传道、授业”是远远不够的, 有 针对性的进行“解惑”才是关键。这就要求教师要转换教学 角色, 教学过程中采用全新的教学模式 (彻底摒弃以教师 为中心、以学生为知识灌输对象的传统教学模式)。建构 以学生为中心的教学过程, 需要营造包括情境、协作、会 话和意义等, 创设良好学习环境。[5]无论教学模式与否, 无疑是要呈现更加有效的课堂学习。那么何为有效的课堂 呢? 将“有效”与“教学”分开理解, 所谓“有效”, 即是要让 学生在规定时间内经历教师教学后, 得到相应成长或者发 展。[6]换句话说, 学生的成长和收获才是评价课堂有效 性的标准而非教师准备是否认真, 进度是否完成等。而“教 学”, 是指教师引起、维持或促进受教者学习的一系列过 程。[6]可见激发学生学习兴趣为学生学习搭桥铺路的历程 才是关键。那么“有效教学”则是通过一系列的教学设计和 教学实践, 让学生在学习上、行为上获得效益, 通过规范、 明确且多样的教学过程, 完成预定的教育目标, 提升学习 成功的比例。[7]

\section{2. 研究目的}

笔者认为, 为了更好的落实“素养”导向, 提升教学质 量和效率，进行“有效教学”就必须结合新兴的科技手段， 调动学生学习兴趣, 利用有限的时间 “无限”的学习知识。 此处的“无限”即指不拘泥于教材本身和课堂时限, 让课堂 不仅是“知识的课堂”更是“智慧的课堂”，让课堂成为激发 学生学习兴趣的钥匙, 开启更为广阔的学习空间, 将知识 延展到生活中去。综上所述, 本研究目的如下:

探讨科技手段融入小学低年级语文课堂是否会激发 学生学习兴趣。

探讨小学低年级语文课堂中的有效教学是否会提升 学生的学习素养。

探讨小学低年级语文“智慧课堂”的建构所需要素。

\section{3. 文献综述}

\section{1. 教育技术}

现代生活与科技息息相关，新兴科技产品逐渐在生活 中成为了不可或缺的一部分, 提高了人们生活的质量和效 率。随着科技的发展, 生产力的不断提高, 教育的模式也 在不断升级, 迎接我们的是将是“教育 4.0 ”时代。教育技术 和设备对教学活动的支持从“三尺讲台一本书”到“多媒体” 设备的运用“电脑和投影”，再到“互联网+”时代，智慧教 室的建构。智慧教室的“智慧性”涉及多方面内容，可概括 为内容呈现 (Showing)、环境管理（Manageable）、资 源获取（Accessible）、及时互动（Real-time Interactive）、 
情境感知（Testing）五个维度，简写“S.M.A.R.T.”。［8] 智慧教室可以帮助教师对学生做出客观、全面、真实的评 价 (智能评价), 在此基础上对学生的学习过程进行有效 的干预。［9］可见技术在课堂上的应用最终会带来很多 好处, 可以丰富学生的学习经验。并且, 与其他在教育领 域红极一时的潮流不同, 科技是一直存在的, 而且很可能 随着时间的推移, 科技在学校的使用会显著增加。 [10]

\section{2. 有效教学}

“有效教学”的研究立足于理论与实践的结合, 是教育 学者与一线教师共同关注的话题。与单纯的“教学”活动相 比, 有效教学除了是教师、学生、教学内容相互作用的统 一活动外, 它超越了教学的基本含义, 所指向的教学具有 较好的效果, 是一种“成功的教学”。[11] 有效教学是一 种提倡效果、效益、效率三者并重的教学观。同样, 有效 果、有效用、有效率是其涵盖的三个具体方面。 [12] 我 们不可否认, 有效教学是许多因素的综合结果, 包括教师 生活背景、和学生的互动以及特定的教学方法。但有效教 学的本质, 就是要考虑到学生的学习。 [13] 那么在这个 动态的、发展的、复杂的系统作用过程中, 有效教学是人 们在特定教学价值观支配下, 依据相关教学研究, 所描绘 的一种理想状态下的教学愿景。 [14] 由此可以看出, 在 教学现场实施有效教学可以以尽可能少的时间、精力和物 力的投入, 取得尽可能多的教学效果, 产生尽可能好的教 学效益, 从而实现特定的教学目标, 满足社会和个人的教 育价值需求而组织实施的活动。 [15]

\section{3. 智慧课堂}

“智慧课堂”, 简单来讲就是用智慧营造出的课堂, 它 是教育思维和教育情感互动的产物, 是师生智慧互动共 生的过程与结果。[16]智慧课堂教学的本质是一种追求创 造性与智慧型的教学, 具体而言, 其教学理念主要体现在 以下三个方面: 以发展学生智慧为目的的教学观, 以促进 师生情智交流为中心的过程观, 以关注发展过程为导向的 评价观。[17]智慧课堂的建构需要实现真正的“教学相长”, 要求学生和教师利用最少的教学实践, 将各自的收获最大 化。这就需要将现代化的科技手段融入课堂。正如台湾学 者张奕华教授所提出的智慧教育“SMARTER”模型, 指以 学生为中心 (Student-centered approach) 的教学与学习方 式、能透过多元取向引起学生学习动机 (Motivate students to learn)、无所不在的让学生使用任何载具 (Any-device) 接近学习入口、提供丰富的学习资源 (Resource availability and diversity) 和科技支持与服务（Technology support and service）教学和学习、教师以科技创新教学和精进教学 （Refinement of Teaching），以及透过诊断工具和云端服 务供即时的学习评量（Evaluation of Learning）结果。[18] 换句话说, 也就是在教学过程中尽量让学生参与, 让学习 过程社会化。[19]台湾网奕资讯科技有限公司为提供“享受 $\mathrm{e}$ 化、优质学习”的教学需求, 发展卓越的教学科技 ( e-Teaching), 让老师们在课堂教学现场, 能够 发挥有效率的多重感官教学; 发展学习科技 (e-Learning) 的应用, 创造学习的无限可能。开发
完成了HiTeach互动教学系统、HiLearning电子书包 学习系统、IRS即时反馈系统、 clouDAS云端诊 断分析服务、ezStation智慧型录制系统等科技组成 的集软件、硬件、云端、服务一体的智慧教学支 持系统一一醍摩豆 (TEAM Model) 智慧教室系统。 [20]智慧课堂的建构即是让教学过程借由科技的辅助, 提 高师生间的互动, 创造更多学生与知识间的联结, 使学习 过程更加高效。

那么, 针对小学低年级的语文课堂来说, 构建智慧课 堂就要在以教学内容为基础, 把握语言文字, 挖掘生活资 源, 进行跨学科的以主题为中心的教学计划, 实施整合教 学。即模糊学科领域的概念和界限限制, 将原有的需要学 习的片段知识, 视为新知与经验的连续整合, 让学生对自 身以及世界有更深、更广的了解。[21]以此学习过程为前 提, 实现自我发展, 提升素养。

\section{4. 结论及建议}

通过阅读文献和课例研究, 我们必须承认, 智慧课堂 的教学模式是配合实现“素养导向”应运而生的产物, 更是 21 世纪课堂的发展趋势。从课前到课上乃至课后, 都以学 生的发展为考量。本文在综合其它学者研究的基础上, 希 望建构的小学语文智慧课堂, 并针对课例分析后给予如何 建构、实施的智慧课堂有效教学教学的建议。

\section{1. 激发兴趣自主学习}

小学低年级学生, 正在面临“幼小”衔接时身份的转变, 各自带着不同的学习基础走进语文课堂, 在需要学习的知 识中, 很多学生已经掌握或是了解, 但还有程度较弱的学 生存在。那么让学生在原有基础上得到提高, 激发学生潜 能才会创造出焕然一新的课堂。例如, 《秋天》一课,

它不仅仅是“部编版”第一册语文教材中的第一篇课 文, 也是我们的学生在小学阶段进入阅读学习的起始。立 足此课的教学设计, 为了让学生“学有所得”, 以一课, 开 启学生一生的“悦读”之旅。在课前, 向学生发放导学单, 让学生自主圈画会读、会认的字, 进行自主提问, 孩子在 课前便已对即将学习的课文充满向往。回收之后, 便能综 合学生的学习特点和心理特点, 掌握好学情进行教学设计。 课程摒弃教师教, 学生学, 一味讲授、灌输的传统教学模 式。利用学生导学的问题进行导入, “秋天来临时会出现 哪些变化呢? ”孩子们很容易发现这是他们自己提出的问 题, 便兴趣盎然地进行讨论、回答。从一开始便调动每个 孩子的学习兴趣, 全员学习。紧接着, 以书中插图“小松 鼠”为学习伙伴, 以“收集松果”为学习情境, 充分考虑低 年级学生的心理特点, 把在导学中学生出现认读困难的字 词, 进行分类, 难度大的为“大松果”难度低的为“小松果”, 以针对不同层面的学生。在此环节, 一颗一颗的“松果”, 通过电子白板进行互动教学的过程, 被同学们亲手送到了 松鼠家, 在不知不觉中不仅巩固了该课需要复现的词语, 更是渗透了“乐于助人”的良好品德, 让老师退为“二线”, 以学生问题为开始, 围绕学生参与展开的自主学习。 


\section{2. 开展活动有效学习}

崔峦先生曾说“识好字、写好字、读好文”是低年级语 文教学的重中之重。在语文课堂上为了促进不同层次的学 生在课堂中的学习可以各有收获, 可以实现“有效教学”。 需要教师在备课时, 紧密贴合学生学情, 打破学科界限, 努力进行学科整合教学, 借形象直观的教学手段, 融入新 兴科技技术, 让学生在有限的时间里, 进行内容更为丰富 的学习。

《全日制义务教育小学语文课程标准》明确对识字写 字进行了如下要求: “要运用多种识字教学方法和形象直 观的教学手段, 创设丰富多彩的教学情境, 提高识字教学 效率。”而在第一学段则更是需要培养学生“喜欢学习汉字, 有主动识字、写字的愿望, 努力养成良好的写字习惯。”[22]

在进行《小青蛙》一课的识字教学时, 为了让学生巩 固“字族”识字的概念, 教师多会采用“圆盘”活动或者儿歌 记忆的教学设计。“圆盘”活动即把一个大圆盘和一个有一 个镂空圆盘的中心点固定在一个轴上。镂空圆盘的中央写 一个基本字, 大圆盘四周分别写着几个不同的部首, 每转 动一次位于上面的镂空圆盘会从空格处呈现出大圆盘上 的一个部首, 与其基本字组成一个不同的字, 学生通过转 动圆盘, 进行识字、组词的练习, 以此来进行字族识字的 巩固。此种方式的教学活动虽然达到了活跃课堂气氛、让 学生亲身参与的目的, 在一定程度上达到了字族识字的教 学目标, 但教师在制作教具时所需时间长, 多班共用需要 回收, 在选择部首时也难免会有疏漏。如果能利用科技辅 助, 诸如“2Kids学汉字” (一款幼儿识字教学APP) 内可以 进行笔顺的展示, 让孩子跟随书写。同理, 若利用相应的 “字族”归纳类闯关游戏程序, 在课堂上让学生在IPAD上点 击, 将“圆盘”活动升级, 不仅汉字数量升级, 画面质感升 级, 游戏趣味性也大大增加。而且课上可以进行的教学巩 固, 回家后也可以进行重复学习。不言而喻, 科技的运用 在打破教学环境的限制, 利用数据丰富教学内容的同时, 寓教于乐。另外, 利用电子白板或提前制作好的flash动画 等, 均可将“加一加”“减一减”“换一换”等识字方法和过程 清晰呈现。在《口耳目》识字课的教学中, 为了让学生了 解“象形字” 的识字方法, 可以通过电子白板和相关多媒体
互动系统, 在展示字形演变的动画前, 先将教学任务分配 到学生的接收装备（如IPAD）上, 让学生组内画一画、 说一说, 在实践后学生将作品直接通过教学系统推送回教 师的电子白板上, 有效盘活课堂生成和学生已有的知识, 进行伙伴间的学习。再进行教师演示, 最后让学生再次绘 画进行生活中象形字的拓展学习。相比以往粉笔、字卡、 教师讲演、投影展示的识字模式, 有着“多、快、好、省” 的特点。课堂中内容变多了, 不再是教材本位; 课堂节奏 变快了, 不再是教师滔滔不绝; 课堂氛围变好了, 不再是 无人问津; 课堂“代表”省去了, 全员参与共同实践。利用 教学系统和科技设备, 将课堂交还于学生, 发挥学生合作 学习、主动思考的主体作用, 落实教学目标, 实现高效教 学, 有效学习。

又如《秋天》一课的阅读教学, 虽然在进行课文学习 时, 利用传统教学方式, 学生通过自由朗读、学生带读, 师生对读的方式, 发现了秋天来临时, 天气和树叶发生的 变化。然而, 在进行在理解重点词语“一片片”时, 究竟什 么叫“一片片”, 学生有想法、却无法清晰表达词意, 陷入 教学困境。此时, 教师进行活动设计, 将词语理解和儿童 歌曲《秋天》的演唱相结合, 利用视频资源和音乐活动创 设情境, 让学生张开手掌模拟枫叶飘落时的场景, 顺势而 导“这片叶子在向我招手呢！这片小叶子在跳舞呢！这么 多叶子在一起就是......”“一片片叶子! ”学生跳脱出传统 教学模式中, 以词解词的方式, 让学生通过一个小活动, 将词语的理解在学生的肢体动作中, 轻松、快速的完成。 如果能将新兴教育科技“VR眼镜”带入课堂, 利用科技带 领学生置身于真实情境中, 带学生漫步落叶飘落的枫叶林, 置身于满山红遍的山谷, 在观看VR的过程中, 不仅将对 抽象词语的理解通过科技手段形象化, 简单化, 明朗化, 而且让学生领略了祖国的大好河山, 扩展了视野, 相信学 习的时效性更会大大提高, 使语言的积累, 融情入境, 跃 然纸上。除此之外, “VR眼镜”能助推学生的想象, 让学 生处在无边的草原上, 随着视野的改变, 身临其境的感受, 秋天天空的“蓝”和“高”, 学生融情入境, 不知不觉地便能 用朗读展现出了秋天天空的特点。

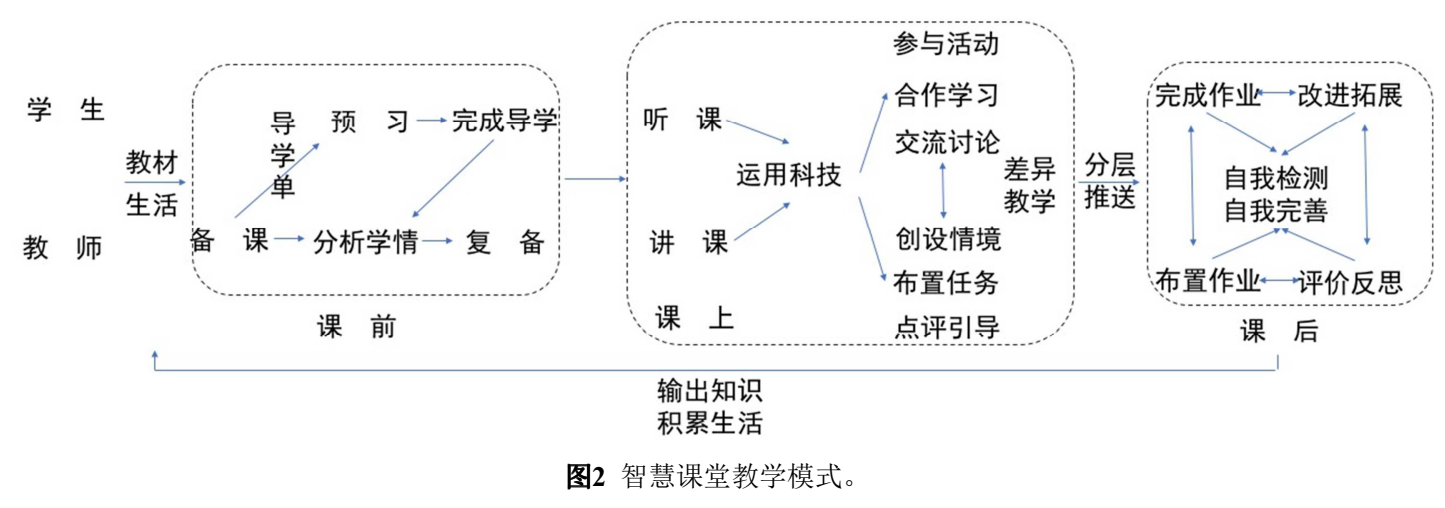

除此之外, 结合“素养”导向进行跨学科且高于学科的 综合性学习育人目标, 学生对知识的诉求不仅停留在课文 内容本身, 不局限于读通文章、读懂文章。很多学生都想 知道大雁在南飞的时候, 为什么“一会儿排成个“人”字, 一

会儿排成个“一,字? ”然而在语文课堂中如何针对这一科 学学科的学习内容进行讲解呢? 利用小组讨论、学生回答、 教师讲解的形式, 虽也能讲授清楚, 但费时费力, 更是无 法确保全员的掌握情况。只有结合科技教学, 如微课播放, 
利用短短 3 分钟的 “小而精”的微课讲授, 不仅能帮助学生 更为直观的了解了大雁飞行的奥秘, 同时也为指导读好这 一长句的停顿做以铺垫。如能利用新兴的教育科技系统 - Interactive Response System（简称IRS系统），即利用 个人手持信号发射器和教室内信号采集器, 实现全员参与 的生生互动, 师生互动。在学生提出问题后, 利用手持遥 控器和系统进行初次作答, 了解班级内掌握情况。再进行 微课的推送, 观看后利用“抢答、挑人等功能”及时呈现学 生学习时的困难点, 利用班内学生已有的学生资源, 进行 差异化教学, 推进课堂的进行把握课堂节奏。将科学知识 借科技手段巧妙的融入语文课堂, 会让学生的学习更加有 效!

\section{3. 走进生活拓展学习}

核心素养是对学生综合性的要求, 因此需要教师在课 堂上不局限教学内容本身, 将知识进行延展。在学习《四 季》一课时, 对语文的学习更不能止于课程, 学生的学习 更不能止于课上, 要带领学生进行延展性的教学。首先, 开展贴近生活, 体验实践。让学生走出校园, 走进公园, 参与丰富多彩的主题活动, 捡拾落叶, 绘制图画, 吟诵诗 歌, 聆听自然, 进行创作交流。再将此素材加以整理回归 课堂, 以学生的作品作为教学资源, 再引导他们以各种形 式表达自己亲历四季,

体验四季的愉悦心情, 最后进行拓展阅读, 达到积累 生活, 拓展学习的目的。

综上所述, 对比以往教、学单一、枯燥的模式, “智 慧课堂”的教学建构 (如图2), 要求教师准确把握学生学 情, 从学生的问题开始着眼, 进行教学设计, 通过活动和 体验实现知识的传授, 让全班参与, 人人进步。智慧课堂 的建构更离不开教学科技的使用和支持, 通过科技手段, 在课前进行课程相关内容资料的收集, 制作教学课件可利 用的科学技术 (如VR、IPAD、IRS系统等), 整合教学 资源; 在课上, 利用电脑、电子白板等科技手段, 让学生 在课上进行教学活动, 提高学生参与度; 在课后, 进行针 对性、差异化作业的布置和评价, 进行知识的拓展或补救。 总体来说通过科技构建的“智慧课堂”就是“化繁为简”的 过程。[23] 将繁复的知识简单化, 将繁圥的学习过程和教 学过程精简化, 激发学生学习的主观能动性的同时, 让学 生在有限的时间里快速、高效的进行学习, 让教师在有限 的课堂上传播更为丰富的知识, 高效的进行教学。让课堂 上的教学和学习都不止于课堂, 习得知识的同时, 学会与 生活建立联结, 形成知识与生活、学习与运用的闭环。

相信“智慧课堂”的建构, 无论对教师还是学生都是更 加理想的课堂模式, 通过科技手段, 通过“智慧课堂”的建 构立足学生需求, 进行学科整合, 拓展学习空间, 实现教 学合力, 在课堂上实现教学相长, 让学生和老师, 学习和 教学一课一收获, 一课一提升。

\section{致谢}

笔者以部编版低年级小学语文课堂的教学设计为基 础, 借鉴大量文献, 试图探索如何利用科技进行教学活动
的锦上添花, 激发学生的学习兴趣, 建构小学语文低年级 “智慧课堂”。旨在发掘现代化、科技化、高效化的课程模 式, 促进教师和学生的有效教学和学习, 全面发展, 提升 素养。

\section{参考文献}

[1] 核心素养研究课题组.中国学生发展核心素养[J].中国教育 学刊,2016,(10):1-3。

[2] 钟启泉.基于核心素养的课程发展:挑战与课题[J]. 全球教育 展望,2016,45(1):3-25。

[3] 方明生,沈晓敏.日本基础教育课程改革的动向及若干分析 [J].全球教育展望,2001, 30(4).

[4] 赵培培. 智慧课堂: 优化与创新传统课堂 [J]. 教育现代 化,2017,4(14):177-180.

[5] 何克抗.建构主义一革新传统教学的理论基础(上)[J]. 电化 教育研究,1997(3):3-9.。

[6] 崔允漷. 有效教学：理念与策略（下） [J]. 人民教 育,2001(7):42-43。

[7] 林進材.有效教學一理論與策略.[M]台北: 五南圖書出版公 司,2000:23-30。

[8] 黄荣怀、胡永斌、杨俊锋、肖广德. 智慧教室的概念及特征 [J].开放教育研究,2012,(2):22-27。

[9] 何克抗. 智慧教室+课堂教学结构变革——实现教育信息化 宏伟目标的根本途径[J].教育研究, 2015,(11): 76-81。

[10] Hicks, S. D. Technology in today's classroom: Are you a tech-savvy teacher? [J]. The Clearing House: A Journal of Educational Strategies, Issues and Ideas ,2011, 84(5), 188-191.

[11] 吴亮奎.教学,有效教学和好的教学——教学概念的话语伦 理分析[J].中小学教师培训,2018,(1): 29-31。

[12] 余文森. 有效教学三大内涵及其意义 [J]. 中国教育学 刊,2012,(5): 42-46。

[13] James, H.Stronge. Qualities of effective teachers [M].林世健, 译.台北: 正中书局,2003:94-101。

[14] 张廷凯.基于课程资源的有效教学研究 [J].课程.教材.教 法,2012,(5):3-7。

[15] 余文森. 有效教学三大内涵及其意义 [J]. 中国教育学 刊,2012,(5):42-46。

[16] 吴永军.关于智慧课堂的再思考 [J].新课程研究(上旬刊), 2008,(4):5-7。

[17] 吴晓静,傅岩.智慧课堂教学的基本理念 [J].教育探索, 2009,(9):11-13。

[18] 张奕华. 台湾科技领导与教学科技发展协会 [Z].http://www.ttlitda.org/index.html. 
[19] Kolb, Liz. SMART Classroom-Tech INTEGRATION: By asking the right questions, school leaders can coach teachers to use technology to drive deeper learning [J]. Educational Leadership,2 019, 76 (5): 20-26.

[20]网奕资讯科技集团.TEAM Model 智慧教室 [Z]。 http://www.habook.com.tw/cn/download/TEAM_Model/TEA M_Model_Smarter_Classroom_Simp.pdf.
[21] Donald P. Kauchak, Paul D. Eggen. Learning and Teaching: Research-Based Methods [M].丘立岗, 译.台北: 学富文化, 2006:144-146。

[22] 教育部.义务教育语文课程标准 [Z]. 北京: 北京师范大学出 版社, 2011。

[23] 郑丽雅.资讯科技在教学上的应用 [J].台湾教育评论月刊, 2014,48。 